

\section{As Relações entre Cultura Alimentar e Turismo}

The connections between Food Culture and Tourism

Eloísa Pereira Barroso ${ }^{1}$

Thalita Kalix G. Santana²

1 Prof. - Dr. - credenciada ao programa de pós-graduação do Departamento de História e ao Centro de Excelência em Turismo (CET) da Universidade de Brasília (UnB). Professora Adjunta 3. Email: eloisabarroso@uol.com.br.

2 Mestranda do programa de Mestrado Profissional do Centro de Excelência em Turismo (CET) da Universidade de Brasília (UnB). Email: thalitakalix@gmail.com. 


\title{
Resumo
}

O presente artigo tem a finalidade de aprofundar na discussão das relações entre cultura alimentar e turismo. Em um contexto de maior evidência comercial da gastronomia brasileira internacionalmente, haveria uma relação entre ela e o turismo no país? Para responder à essa inquietação, trata-se, através de uma revisão teórica, da formação da cultura alimentar e de como, a partir dos conceitos de cultura, identidade e memória, foram se construindo alguns dos aspectos das culturas alimentares brasileiras. A partir disso, discute-se a formação do turismo como fenômeno moderno e como se dá sua relação com a cultura alimentar. Finaliza-se analisando o processo de construção de entendimento dessa relação no Brasil. Aponta-se que os diversos aspectos da cultura alimentar brasileira podem ser utilizados para políticas públicas de fomento do turismo gastronômico no país: valorizando a identidade cultural e empoderando as populações locais.

Palavras-chave: Cultura Alimentar; Turismo; Gastronomia; Identidade; Memória.

\begin{abstract}
This paper aims to discuss the connections between Food Culture and Tourism. In a context in which Brazilian Gastronomy has had an international evidence, would it have in the country any relation between Food Culture and tourism? In an attempt to answer this question, this paper draws a theoretical review of Food as cultural construction. To do so, it goes through the concepts of culture, identity and memory - and how they build up some aspects of Brazilians Food Cultures. From there, it presents the discussion of Tourism formation and how it relates to Food Culture. It ends analyzing how this relation's process is constructed in Brazil. It is pointed out that the diversity of Brazilian Food Culture aspects can be used by public politics to foment the Gastronomic Tourism in the country: valuing the cultural identity and empowering local populations.
\end{abstract}

Keywords: Food Culture; Tourism; Gastronomy; Identity; Memory. 


\section{INTRODUÇÃO}

Nos últimos anos, o Brasil ganhou notoriedade mundial em diversos aspectos. Um deles foi a sua gastronomia - evidenciada pela a ascensão do chef Alex Atala e seu restaurante, D.O.M., que figura entre os 11 melhores do mundo desde 2011. Os ingredientes exóticos, principalmente amazônicos, ganharam roupagens e técnicas modernas nas mãos do cozinheiro e conquistaram profissionais da gastronomia na Europa e América do Norte. No entanto, a culinária brasileira ainda é um grande mistério para a maior parte dos estrangeiros. Raramente a culinária figura entre as primeiras associações ao país.

De acordo com uma pesquisa realizada pelo Ministério do Turismo em 2009 denominada "Hábitos de Consumo do Turismo Brasileiro", a gastronomia local é apenas o sétimo item de importância para os brasileiros escolherem seu destino de viagem pelo próprio país, tendo peso de $2,7 \%$. Entre as atividades realizadas durante a viagem, conhecer pratos e comidas típicas é citado por somente $11 \%$ dos viajantes. Há, contudo, um detalhe interessante: quando o destino é a região Norte, essa passa a ser a segunda atividade mais citada, com $21,4 \%$, atrás apenas de passeios para conhecer pontos turísticos, com 35,9\%.3

Em uma análise superficial, podemos concluir que o exótico da culinária amazônica chama a atenção. Entretanto, a cultura alimentar brasileira, com toda a sua diversidade, ainda não parece ter uma relação direta com o desenvolvimento do turismo no país. Como ressalta Susana Gastal (2005): “Hoje, o desconhecido está menos ligado aos territórios - praticamente inexistem no planeta territórios ainda intocados pelos humanos - e mais associado a hábitos sociais ou a práticas culturais de grupos diferentes daquele do viajante".

Este trabalho tem a finalidade, portanto, de aprofundar a discussão das relações entre cultura alimentar e turismo, através de uma revisão teórica. Para tanto, o presente ensaio baseia-se nas correlações feitas entre os conceitos de cultura, identidade e memória por autores como Clifford Geertz, Zygmunt Bauman, Stuart Hall, Pierre Nora, Michael Pollak, Maurice Halbwachs, Paul Ricoeur e Homi Bhabha. Embasado em Jacques Le Goff, Nobert Elias e Carlos Alberto Dória, o ensaio discorre sobre a construção de uma Gastronomia Brasileira na modernidade. Por fim, apoia-se em Jost Krippendorf, Susana Gastal e Marustchka Moesch e Julia Csergo para discutir a formação do Turismo e sua relação com a Gastronomia.

Assim, o primeiro tópico trata da formação de cultura alimentar e como, a par-

3 Disponível em <http://www.turismo.gov.br/sites/default/turismo/noticias/todas_noticias/Noticias_download/13.11.09_Pesquisa_Hxbitos_2009.pdf>. Acessado em 14 jun. 2016. 
tir dos conceitos de cultura, identidade e memória, foram se construindo alguns dos aspectos das culturas alimentares brasileiras. Na segunda parte deste ensaio, discute-se a formação do turismo e sua relação com a cultura alimentar. Encerra-se com apontamentos finais acerca do processo de construção de entendimento dessa relação no Brasil.

\section{CULTURA ALIMENTAR: "DIZE-ME O QUE COMES E TE DIREI QUEM ÉS"4}

Antes de discutir qual a relação entre gastronomia e cultura é preciso definir o que é cultura. Geertz (1989) nos apresenta o conceito de cultura como a teia de significados que constitui o homem, ao qual ele está amarrado. A cultura seria então formada pela experiência, a vivência cotidiana que constrói significados. E, por isso, é coletiva, uma vez que, a criação de significados acontece na interação com o Outro. Isto é, só é possível construir significados que possam ser reconhecidos coletivamente, ou eles não fazem sentido. Essa ideia se apoia no conceito de alteridade, segundo Bauman (2012), que ressalta a face social do ser humano. Para ele, o sujeito só se reconhece como tal ao se ver no Outro e se perceber diferente. É ao reconhecer as minhas diferenças em relação ao outro que me identifico.

Essa capacidade única de reproduzir e produzir novas estruturas, e não simplesmente a habilidade de introduzir intermediários simbólicos no espaço entre a consciência do evento em si, dota a linguagem humana de seu potencial gerador de cultura e a transforma no verdadeiro alicerce da cultura como fenômeno (BAUMAN, 2012, p. 146).

O ser humano tem, portanto, uma existência significada no espaço cultural, mas não dissociada do biológico. Geertz dialoga com essa perspectiva quando apresenta a ideia de que a cultura não é pré-determinada pela natureza, como se acreditava até então. Para o antropólogo norte-americano, a cultura não é dada, mas sim construída socialmente. "Nós somos animais completos e inacabados que nos completamos e acabamos através da cultura - não através da cultura em geral, mas através de formas altamente particulares de cultura" (GEERTZ, 1989, p. 36). Isso significa que não se pode falar em uma cultura humana, ou uma cultura homogênea, mas de culturas que se diferenciam de acordo com os grupos sociais pelos quais foram construídas.

Nessa perspectiva, a cultura está associada, necessariamente, às noções de tem-

4 Brillat-Savarin nos aforismos da Fisiologia do Gosto. 
po e espaço. Não é possível falar de uma cultura universal. A cultura, uma vez construída socialmente, é particularizada e terá suas variações de acordo com a época e com o território nos quais se insere. Por exemplo, de acordo com essa linha de pensamento, não se pode falar da cultura quilombola de uma forma geral, mas sim da cultura dos Kalungas nos dias de hoje ou a cultura dos quilombolas do Mesquita na década de 1950.

Além disso, por ser resultado da construção humana, a cultura, nesta visão, está sempre em transformação. Isto é, por se tratar de uma teia de significados construída pela experiência dos homens em um espaço e tempo específicos (GEERTZ, 1989), a cultura é ressignificada constantemente, ela não é estática ou fixa, como muitas vezes se faz acreditar. Ao contrário, a cultura tem como parte de seu processo de construção ir se modificando e criando novos significados.

[...] a imagem de uma natureza humana constante, independente de tempo, lugar e circunstância, de estudos e profissões, modas passageiras e opiniões temporárias, pode ser uma ilusão, que o que o homem é pode estar tão envolvido com onde ele está, quem ele é e no que ele acredita, que é inseparável deles. É precisamente o levar em conta tal possibilidade que deu margem ao surgimento do conceito de cultura e ao declínio da perspectiva uniforme do homem (GEERTZ, 1989, p. 26).

Portanto, o recorte do qual estamos tratando ao tentar responder à questão de qual a relação entre gastronomia e cultura é de aspectos referentes à cultura alimentar brasileira, nesse início de século XXI. Vive-se numa era que o sociólogo jamaicano Stuart Hall (2006) definiu como modernidade tardia, marcada pela extrema fragmentação da identidade. Nessa perspectiva, é bastante complexo falar sobre uma identidade gastronômica brasileira geral ou harmônica. De acordo com Hall, o sujeito da modernidade tardia se desloca por diferentes identidades, não mais se atendo a uma única, como era na modernidade. Não há mais um único grupo com o qual se identificar, mas vários pelos quais se pode transitar - em um processo em que as diferentes identidades podem ser somadas.

Por outro lado, seguindo essa mesma linha de pensamento, há uma fragmentação excessiva e uma aceleração do tempo, que são características fundamentais da modernidade tardia, e que podem gerar inseguranças no sujeito: não há mais a certeza de se identificar com um único grupo, ao contrário, há infinitas possibilidades de escolhas. Segundo Pierre Nora, é neste contexto que surge a necessidade do sujeito de se referenciar nas tradições do passado. Trata-se de uma forma de encontrar uma coerência que se perde em um mundo de identidades fragmentadas, a busca de uma materialidade da identidade. "Como não ver, nesse gosto pelo cotidiano no 
passado, o único meio de nos restituir a lentidão dos dias e o sabor das coisas? “ (NORA, 1993, p. 20).

Nesse sentido, para se discutir esse apego ao tempo passado na contemporaneidade, o movimento referenciado nas tradições ganha força no processo de construção de uma identidade cultural. Nessa perspectiva, com o passado e as tradições em evidência, é importante tratar aqui do conceito de memória, pois como argumenta Pollak, "a memória é um elemento constituinte do sentimento de identidade, tanto individual como coletiva, na medida em que ela é também um fator extremamente importante do sentimento de continuidade e de coerência de uma pessoa ou de um grupo em sua reconstrução de si" (1992, p. 204). Ou seja, a memória é fundamental no processo de construção das identidades.

Entre essas lembranças estão as gastronômicas. Quando pensamos em cultura alimentar, podem ser despertadas em nós lembranças e inquietudes: como, dentre todos aqueles alimentos degustados ao longo da vida, se escolhe apenas um que define como "aquele" com o qual pessoa se identifica? Para isso o sujeito precisa ativar suas memórias gastronômicas. É pertinente aqui o exemplo desse processo de memória ligada à gastronomia encontrado quando Proust descreve, com extrema riqueza de detalhes, as madeleines que, ao serem saboreadas o fazem se transportar ao passado5. Esse trecho deixa claro toda a complexa teia que envolve o ato

5 "Quando, por um dia de inverno, ao voltar para casa, vendo minha mãe que eu tinha frio, ofereceu-me chá, coisa que era contra meus hábitos. A princípio recusei, mas, não sei por que, terminei aceitando. Ela mandou buscar um desses bolinhos pequenos e cheios chamados madalenas e que parecem moldados na valva estriada de uma concha de São Tiago. Em breve, maquinalmente, acabrunhado com aquele triste dia e a perspectiva de mais um dia tão sombrio como o primeiro, levei aos lábios uma colherada de chá onde deixara amolecer um pedaço de madeleine. Mas no mesmo instante em que aquele gole, de envolta com as migalhas do bolo, tocou meu paladar, estremeci, atento ao que se passava de extraordinário em mim. Invadira-me um prazer delicioso, isolado, sem noção de sua causa. Esse prazer logo me tornara indiferente às vicissitudes da vida, inofensivos seus desastres, ilusória sua brevidade, tal como o faz o amor, enchendo-me de uma preciosa essência: ou, antes, essa essência não estava em mim, era eu mesmo. Cessava de me sentir medíocre, contingente, mortal. De onde me teria vindo aquela poderosa alegria? Senti que estava ligada ao gosto do chá e do bolo, mas que o ultrapassava infinitamente e não devia ser da mesma natureza.

[...] E de súbito a lembrança me apareceu. Aquele gosto era o do pedaço de madeleine que nos domingos de manhã em Combray (pois nos domingos eu não saía antes da hora da missa) minha tia Léonie me oferecia, depois de o ter mergulhado em seu chá da Índia ou de tília, quando ia cumprimentá-la em seu quarto. O simples fato de ver a madeleine não me havia evocado coisa alguma antes que a provasse; talvez porque, como depois tinha visto muitas, sem as comer, nas confeitarias, sua imagem deixara aqueles dias de Combray para se ligar a outros mais recentes; talvez porque, daquelas lembranças abandonadas por tanto tempo fora da memória, nada sobrevivia, tudo se desagregara; as formas - e também a daquela conchinha de pastelaria, tão generosamente sensual sob sua plissagem severa e devota - se haviam anulado ou então, adormecidas, tinham perdido a força de expansão que Ihes permitiria alcançar a consciência.

[...] E mal reconheci o gosto do pedaço de madeleine molhado em chá que minha tia me dava (embora ainda não soubesse, e tivesse de deixar para muito mais tarde tal averiguação, por que motivo aquela lembrança me tornava tão feliz), eis que a velha casa cinzenta, de fachada para a rua, onde estava seu quarto, veio aplicar-se, como um cenário de teatro, ao pequeno pavilhão que dava para o jardim e que fora construído para meus pais aos fundos dela (esse truncado trecho da casa que era só o que eu recordava até então); e, com a casa, a cidade toda, desde a manhã à noite, por qualquer tempo, a praça para onde me mandavam antes do almoço, as ruas por onde eu passava e as estradas que seguíamos quando fazia bom tempo." (PROUST, 2006, p. 47) 
de comer, e como a escolha e usos dos ingredientes dizem respeito à ligação com o território e às relações sociais.

Se, para Bauman e Geertz a formação da identidade de um sujeito nasce da alteridade, Halbwachs (1990) e Ricoeur (2007) reafirmam esta ideia ao considerar que ela depende, fundamentalmente, do grupo com o qual esse sujeito se identifica. Os dois autores tratam com profundidade o conceito de memória coletiva. Mas, antes de chegarmos a ele, é necessário ressaltar que a memória, nessa corrente de pensamento, é sempre considerada como fragmentada. Ou seja, Halbwachs (1990) é um dos autores da teoria da memória a defender que não existe uma memória integral do passado. Para ele, o sujeito não consegue se recordar na totalidade de todos os acontecimentos que viveu. $\mathrm{O}$ que ele se lembra são apenas trechos, fragmentos, ou vestígios que são reordenados no momento em que são recordados e representam o passado no presente. É um sabor, um cheiro - um fragmento de lembrança - que se reordena no presente com outros 'pedaços' de memória e formam a recordação.

A memória, desse ponto de vista, é sempre ressignificada. Isto porque, de acordo com Halbwachs (1990) e Ricoeur (2007), cada vez que recordamos uma lembrança, que fazemos o movimento de trazê-la do passado para o presente, a ressignificamos, pois ela é colocada e revivida em outro contexto, em outro tempo e espaço. Não é mais aquele momento que foi vivido, mas sim uma representação daquele passado. Ricoeur argumenta que, o presente é muito fluido, o agora já virou passado, e, por isso, a memória é o passado com perspectiva de permanência para o futuro. "A busca da lembrança comprova uma das finalidades principais do ato de memória, a saber, lutar contra o esquecimento, arrancar alguns fragmentos de lembrança à 'rapacidade' do tempo (Santo Agostinho dixit), ao 'sepultamento' no esquecimento" (RICOEUR, 2007, p. 48).

Como ressaltam os dois autores, não dá para se falar em memória individual pura, pois toda memória é, no mínimo, regida por signos ou imagens, que são formados socialmente. A memória é, portanto, constituída de lembranças, imagens e sentimentos, que se referem, de alguma forma, a outras pessoas. A nossa memória individual é, nessa perspectiva, ligada à memória coletiva do grupo ou dos grupos dos quais fazemos parte. Quando Proust se recorda de seu passado ao degustar uma madeleine, sua tia, os prédios, a rua, cores e sabores, todas essas construções sociais são evocadas. E é como se ele voltasse a experimentar toda aquele passado novamente, no presente.

Ao mesmo tempo, nesse sentido, não se pode falar em memória coletiva sem memória individual. A memória de um grupo vive nas memórias individuais de cada 
um de seus integrantes. Por isso, explica Halbwachs (1990), existem tantas memórias coletivas quanto grupos. Esses são dos mais variados. Durante a vida, o sujeito pertence a diversos grupos: o primeiro de todos é a família; depois vêm os vizinhos, os amigos de escola, os colegas de trabalho, entre outros. Pode-se fazer parte de diversos grupos ao mesmo tempo. As memórias de cada grupo, defende Halbwachs, estão, no entanto, intrinsecamente ligadas à coletividade. Assim, uma vez que o sujeito deixa de fazer parte daquele grupo, suas memórias daquele período são esquecidas e só podem ser recordadas no encontro com outros indivíduos que participavam daquele mesmo núcleo. Dessa forma, a memória individual é ressignificada a partir da memória coletiva.

Mas para se recordar de algo, geralmente, precisa-se de um gatilho que dispare a busca pela lembrança: pode ser o encontro com alguém do grupo a que outrora pertencemos, uma imagem, uma data comemorativa, etc. Na memória coletiva Halbwachs denominou esses gatilhos de lugares de memória. Eles "funcionam principalmente à maneira dos reminders, dos indícios de recordação, ao oferecerem alternadamente um apoio à memória que falha, na luta contra o esquecimento, até mesmo uma suplementação tácita da memória morta" (RICOEUR, 2007, p. 58). É nessa ênfase aos pontos de referência que estruturam a memória coletiva, entre os quais se destacam os lugares de memória, que a gastronomia aparece.

Entre eles incluem-se evidentemente os monumentos, esses lugares da memória analisados por Pierre Nora, o patrimônio arquitetônico e seu estilo, que nos acompanham por toda a nossa vida, as paisagens, as datas e personagens históricas de cuja importância somos incessantemente relembrados, as tradições e costumes, certas regras de interação, o folclore e a música, e, por que não, as tradições culinárias (POLLAK, 1989, p. 3).

Preparos, sabores e aromas são possibilidades de evocação de memórias de grupos diversos. Quem nunca se recordou da casa da infância ao sentir o cheiro da comida que a mãe preparava? Ou, ao rememorar o passado vivido, não sentiu sabores degustados naquela época? A gastronomia está, nessa perspectiva, extremamente ligada à cultura, memória e identidade dos grupos. Cada coletividade da qual fazemos parte tem suas particularidades gastronômicas, sua identidade. Associamos diferentes tipos de preparos e alimentos a cada um dos grupos que fizemos ou fazemos parte. "A alimentação é, por vezes, o suporte de uma identidade que nós pretendemos defender e um recurso a preservar em nome da diversidade cultural" (BIENASSIS, 2011, p.132).

Ainda nessa linha de pensamento, Pollak defende que a memória é herdada, pois ela tem forte conexão com o primeiro grupo do qual o sujeito participa, a família, e 
está conectada ao sentimento de coerência, de identidade. "Nas lembranças mais próximas, aquelas de que guardamos recordações pessoais, os pontos de referência geralmente apresentados nas discussões são, como mostrou Dominique Veillon, de ordem sensorial: o barulho, os cheiros, as cores" (POLLAK, 1989, p. 11). De acordo com esse conceito, pode-se falar que um grupo tem uma cultura alimentar específica? Mais particularmente em relação ao Brasil seria possível definir uma identidade gastronômica brasileira? Se sim, que preparo representaria a culinária de todo o país?

Em face às questões colocadas, é essencial retomar aqui os estudos da memória. Quando se fala de memória coletiva refere-se a um grupo restrito, geralmente pequeno. Tratar de memória nacional, é muito mais do que apenas somar todas as memórias coletivas. Nesse processo de definição da memória nacional, há uma seleção de quais memórias serão salvaguardadas e quais serão ignoradas, abandonadas ao esquecimento. Usualmente esse tipo de escolha é feita pelos sujeitos que têm poder de decisão (e poder político), e, como todos sujeitos sociais, têm intencionalidades, conscientes ou inconscientes. Pode-se dizer que a tentativa de construção pelo Estado de uma memória nacional faz parte de um movimento de autorrepresentação.

Assim, nem todas as memórias coletivas farão parte das lembranças oficiais. Geralmente, poucas fazem. O que ocorre, é uma tendência a homogeneizar as memórias para "criar" uma memória nacional. Bhabha (2003) defende que a identidade nacional existe muito mais como discurso do que no cotidiano, pois a fala oficial nacionalista privilegia uma visão, como se todos fossem um só, ignorando as pluralidades e particularidades existentes no seio do país. E qual seria então o discurso de identidade nacional gastronômica construída no Brasil?

Para chegar a essa construção é preciso contextualizar o problema: na modernidade. Em seu livro "História e Memória", Jacques Le Goff apresenta três diferentes tipos de modernização:

a) a modernização equilibrada, em que o êxito da penetração do 'moderno' não destruiu os valores do 'antigo', que tem como exemplo o Japão, país que manteve suas tradições ao mesmo tempo que se modernizou; b) a modernização conflitual que, atingindo apenas uma parte da sociedade, ao tender para o 'moderno', criou conflitos graves com as tradições antigas, que pode se citar como exemplo algumas nações muçulmanas na África; e c) a modernização por tentativas que, sob diversas formas, procura conciliar 'moderno' e 'antigo', não através de um novo equilíbrio geral, mas por tentativas parciais (LE GOFF, 1990, p. 185).

Nessa linha de análise, podemos dizer que o Brasil passou por um processo de 
modernização por tentativas. Isto é, a modernização ainda não foi completamente efetivada no país: a modernidade (ou até mesmo a pós-modernidade ou modernidade tardia) convivem com o antigo. Ao mesmo tempo, nesse processo, percebe-se que a modernização foi bastante valorada - ao passo em que o antigo foi depreciado - o que pode ser notado já com o lema da bandeira nacional "ordem e progresso". O Brasil assumiu, desde fins do século XIX, o discurso de "país do futuro", o que pode ter corroborado para que a ideologia de uma modernização necessária, em oposição ao antigo, à tradição, ganhasse força em alguns aspectos da vida social.

Nesse sentido, o conceito francês de civilisation, explicado por Nobert Elias (1994) em "O processo civilizador", pode ser visto como um fator influente para o discurso de progresso nacional. Assim como a maior parte dos países ocidentais, o Brasil se inspirou no conceito nascido na França de que a cultura era estratificada: haviam culturas maiores e menores e, claramente, a cultura da aristocracia francesa estava acima de todas. Os costumes do país europeu, nesse movimento, passaram a serem imitados mundo afora. $O$ francês era a língua a ser estudada.

Desde o século XVIII, destaca o folclorista Câmara Cascudo, "com D. João V, a França reinava nas modas do paço real, trajes, ademanes, elegâncias, maneiras." (2011, p. 722). Assim, ressalta, não seria de se espantar sentir a influência da França no Brasil: "O francês é o idioma letrado, enfrentando e empurrando o latim clássico. As festas fidalgas sob D. Maria primeira têm o ar francês do falso bucolismo aristocrático de Fragonard e Watteau" (CASCUDO, 2011, p. 723).

Nesse contexto, a necessidade de ser reconhecido como um povo "civilizado" exigia que os brasileiros renegassem tudo que fosse "bárbaro", quer dizer, tudo que não fosse condizente com a cultura europeia. Um país moderno deveria ter uma "alta cultura". Nesse escopo, a gastronomia popular tradicional, de origem indígena, negra e pobre foi desvalorizada durante séculos. Civilizado e chic era a culinária francesa. Assim a gastronomia europeia passa a dominar as mesas da burguesia nacional.

De fato, ainda hoje é bastante conveniente a ideia de que somos mestiços no prato, mesmo que a maior parte das comidas populares não seja aceita em mesas cultas e elitizadas. E é trabalhando com essas heranças, atenuando seus aspectos mais estranhos, que vamos construindo uma nova cozinha brasileira; afinal, precisamos cada vez mais desse mito num ambiente internacionalizado e competitivo, pois, sem ele, o que seríamos, comparativamente? (DÓRIA, 2014, p. 43)

Pode-se dizer, nessa linha de pensamento, que durante alguns séculos, optou-se porvalorizar uma memória gastronômica burguesa, de inspiração europeia. Ao passo 
que a cultura alimentar vinculada ao popular foi colocada num patamar de "cultura menor". Esse processo só começa a se inverter, ligeiramente, nos últimos anos, como parte de um movimento global de valorização das particularidades e, consequentemente, das localidades. Como ressalta o sociólogo Carlos Alberto Dória:

No período do nacionalismo, contrapunha-se uma 'cozinha brasileira' a uma 'cozinha francesa' ou afrancesada que nos remetia para fora do universo de nossas vivências mais imediatas. E dessa cozinha brasileira eram tributárias todas as cozinhas regionais. Recentemente, contudo, assiste-se à emergência de um localismo extremo, com a atenção e a ênfase voltadas para os terroirs e as demarcações de origem de determinados produtos (DOCS, AOCS etc.). Estas podem, inclusive, se sobrepor às denominações nacionais, mostrando como 'território' é um conceito histórico de poder explicativo bastante variável (2014, p.140).

Retoma-se, assim, a ideia de Nora de que, na sociedade de modernidade tardia, fragmentada e acelerada, há um movimento de busca por uma identidade material que nos devolva a certeza e a lentidão dos tempos passados. É o que o historiador francês denomina de desejo de memória: um reflexo da mundialização, da hegemonia do efêmero6. Por outro lado, essa busca pela revalorização das tradições culinárias vinculadas à cultura popular também pode ser vista como uma resistência à tendência de homogeneização resultante da globalização acelerada. Ou ainda, como uma forma de diferenciar-se em um mercado gastronômico internacional saturado, em um processo de produção de singularidades que pode ser percebido como um movimento presente em todas as esferas no mundo atual.

Mas a preponderância do processo de modernização do Brasil, do progresso, pode ter influenciado ainda mais as tradições alimentares da população do que se perceba em uma primeira análise. Isso porque um dos reflexos da modernidade foi a delimitação do tempo de lazer e a inserção da mulher no mundo do trabalho. Com jornada dupla - trabalhando fora e em casa -, a mulher passa a ter menos tempo para se dedicar à cozinha, local que sempre foi seu na tradição do país, e precisa de alimentos mais práticos. A industrialização da alimentação cresce vertiginosamente em todo o ocidente durante o século $X X$.

Câmara Cascudo, no início dos anos 1960, já apontava essas mudanças como uma vitória “do 'progresso' contra a tradição valorizada da refeição." (2011, p. 37):

O comum, natural, obrigatório e lógico para a mulher em nossos dias é saber improvisar um jantar, enfeitar o prato, disfarçar a fisionomia de cada espécie deglutível com a ciência nefasta dos colorantes mascaradores, das mistificações sugestivas, da incaracterização

6 Conceito que Bauman define como fluidez do mundo. 
gustativa. [...] A industrialização dos alimentos reduz a cozinha a um armário de latas . [...] Um jantar egresso de latas é ato de comer mas não no nível de uma refeição. (CASCUDO, 2011, pp. 36-37)

Isso pode ter impactado diretamente na construção de memórias gastronômicas locais, uma vez que as famílias foram, influenciadas por essa industrialização, mudando paulatinamente seus hábitos alimentares. Assim, comer direto da lata passa a ser visto como bom e naturalizado. E com os costumes alimentares, vai se alterando o gosto.

Outro ponto a ser levado em conta da influência da modernização nas identidades gastronômicas nacionais é o processo de urbanização. É durante a modernidade que a migração do campo para a cidade se acelera. Com o esvaziamento dos campos e o adensamento da malha urbana das cidades, nota-se uma perda dos hábitos de cultivo e extração de hortaliças, frutas e leguminosas. Se no início do século passado era bastante comum as pessoas, mesmo na cidade, manterem o contato com a terra através de quintais com hortas e pomares, isso foi se rareando. Atualmente é possível perceber uma tendência de retomada desses costumes, do pertencimento à terra, dando uma dimensão da ruralidade nas metrópoles. Mas ainda em pequena escala. Não é incomum, entretanto, nos dias de hoje, encontrar jovens que nunca tenham visto um legume in natura. $\mathrm{E}$ isso necessariamente influencia na percepção da população em relação à tradição gastronômica nacional.

Por fim, com a aceleração do ritmo de vida, o "sentar-se à mesa" com a família para partilhar uma refeição deixa de ser uma regra para tornar-se uma exceção. As refeições rápidas, fast food, passam a fazer parte do hábito alimentar ocidental. Na falta de tempo, come-se rapidamente. Nesse contexto, a culinária tradicional, fortemente ligada ao solo, ao território, ao tempo da natureza, perde força. É frente a esse processo que movimentos surgem com o intuito de retomar a valorização da alimentação saudável e de ingredientes locais, que valorizem o saber-fazer daquele território. Saber-fazer este que está ameaçado, uma vez que não é mais transmitido de geração para geração.

\section{CULTURA ALIMENTAR E TURISMO}

Há que se ressaltar que a alimentação humana na perspectiva de Câmara Cascudo é mais do que um ato biológico, ela é fundamentalmente um ato social e cultural. $\mathrm{Na}$ alimentação estão inscritas as práticas sociais dos grupos, nela se inscrevem escolhas, símbolos e subjetividades que se instituem no tempo e no espaço. Dessa maneira, ao ser entendida como representações de uma cultura ela é também um 
«sistema simbólico» no qual se inserem códigos sociais que mediatizam as relações humanas.

Se considerarmos ser a cultura alimentar de um povo criada dentro de processo histórico, podemos afirmar que ela articula um conjunto e significados que estão pautados pela cultura e pela tradição, o que a torna algo singular, dessa maneira ela não é fixa, mas uma constante reconstrução sujeita a processos constantes de ressignificação e recriação temporal e espacial. Nessa perspectiva a cultura alimentar de um povo não se cristaliza em livros ou se reduz a uma lista de alimentos.

Dessa forma, percebe-se que a industrialização e suas consequências sociais, de delimitação do tempo de lazer e de aceleração da vida cotidiana, na contemporaneidade são determinantes na construção de uma cultura alimentar que se quer brasileira. Mas outro fenômeno moderno também tem suas influências nessa formação: o turismo. Trata-se do contato com o Outro (o estrangeiro) e da relação que se opta por construir com quem vem de fora: como o Brasil e sua gastronomia, sua cultura e memória, são representados para essas pessoas. Esta é uma das questões que este trabalho pretende, tangencialmente, responder. Mas, antes, é preciso discutir que turismo é esse.

Se a modernidade modifica a relação da população ocidental com a alimentação, ela é a grande transformadora do turismo na forma que conhecemos atualmente. Pode-se afirmar que este é um fenômeno que se consolida na modernidade. Como ressalta Krippendorf, não é que o homem não viajasse antes, "o ser humano não nasceu turista, mas com a curiosidade e um sentimento um tanto nostálgico quanto aos países longínquos, que gostaria de conhecer. Em todas as épocas, isso esteve entre suas necessidades básicas e imediatas" (KRIPPENDORF, 2000, p. 14). Mas, com o processo de industrialização e a consequente organização do tempo e limitação do lazer, o fenômeno turístico se expandiu.

Ao ponto que, em dezembro de 1948, a Assembleia Geral das Nações Unidas inclui o lazer em um dos artigos da Declaração Universal dos Direitos Humanos. Assim, fica definido: "Artigo 24. Todo ser humano tem direito a repouso e lazer, inclusive à limitação razoável das horas de trabalho e férias periódicas remuneradas" (UNESCO, 1998). No entanto, o que se percebe é que o turismo se desenvolve numa velocidade e proporção superlativas. Dessa forma, sua faceta de atividade econômica passa a ser o foco principal, se impondo às outras dimensões deste fenômeno social.

O turismo é uma combinação complexa de inter-relacionamentos entre produção e serviços, em cuja composição integram-se uma base cultural, com herança histórica, 
a um meio ambiente diverso, cartografia natural, relações sociais de hospitalidade, troca de informações interculturais. O somatório desta dinâmica sociocultural gera um fenômeno, recheado de objetividade/subjetividade, consumido por milhões de pessoas, como síntese: o produto turístico (MOESCH, 2002, p. 10).

É exatamente esta a grande falha apontada pelos pesquisadores do turismo pelo mundo e, especificamente, no Brasil: as políticas públicas na verdade são tratadas pelos órgãos governamentais como políticas de mercado e, consequentemente, acabam por ignorar a complexidade social que envolve o fenômeno turístico. "Considerado a fundo, o processo do turismo não é aquele do indivíduo que viaja, mas aquele da massificação do fenômeno em seu todo. O principal problema do turismo moderno está, na realidade, no volume - no grande volume" (KRIPPENDORF, 2000, p. 66).

Um dos aspectos que a massificação traz para o turismo é a possibilidade de se transformar em uma atividade que causa desequilíbrios. Grandes populações passam a frequentar espaços naturais e cidades cuja estrutura não é capaz de atender a todos. A população local acaba sendo a que mais sofre: se a água e a energia elétrica não são suficientes para todos durante a alta temporada, corta-se o fornecimento dos locais e não das instalações turísticas. "Acontece muito a inversão das prioridades [...]. O turismo engole os terrenos, a natureza e o patrimônio cultural. Torna-se um novo colonizador e destrói o meio ambiente" (KRIPPENDORF, 2000, p. 150).

E não é apenas o meio ambiente que se desequilibra com a "invasão" de turistas às regiões receptoras. A estrutura que o turismo exige, de hospedagem, atrações e restaurantes, acaba atraindo mão de obra de outras regiões do país e até mesmo estrangeira, principalmente sob a alegação de falta de capacitação da população local. Assim, os empregos gerados na região concentram-se em funções de baixa remuneração.

\footnotetext{
A invasão é perfeita: do exterior pelos turistas, e do interior pelos novos residentes e mão-de-obra estrangeira. Esse esquema é clássico e ocorre em todos os lugares de forma mais ou menos similar. E quer nos agrade ou não, é assim que o turista moderno denota traços colonialistas (KRIPPENDORF, 2000, p. 81).
}

Além disso, há uma consequente valorização imobiliária das áreas centrais (ou próximas à praia) nessas regiões, que acaba por pressionar os habitantes locais para áreas mais afastadas, onde o custo de vida não se eleva tanto. Esse fenômeno é o que o geógrafo Everaldo Costa (2015) denomina de dialética da construção destrutiva - ao valorizar e patrimonializar os espaços históricos e torná-los turísticos, a população originária é forçada para as regiões mais distantes do centro, levando consigo a cultura que tornou aquele local um atrativo em primeiro lugar. 
Com isso, o patrimônio cultural alimentar também é atingido. A culinária local se transforma. Os ingredientes mudam ou encarecem, a população autóctone migra para a periferia, levando consigo os costumes alimentares. As regiões turísticas são dominadas por restaurantes com padrões internacionais: a comida local ganha nova roupagem, tornando-se mais refinada, e aumenta a disponibilidade de culinária francesa, italiana, americana, entre outras, como relatam Daniel Hiernaux-Nicolas e Carmen González-Gómez sobre esse processo de refuncionalização do centro de Querétaro, no México:

O fechamento progressivo das pequenas lojas e negócios tradicionais como sapateiro, o açougue do bairro, mas também o cabelereiro ou a cantina, implica no desaparecimento de múltiplos odores que formavam parte da paisagem olfativa do bairro. Uns odores desaparecem, outros pareciam surgir do nada: o odor penetrante do pequeno café com suas duas mesas na calçada; a doceria 'francesa' que substitui o odor das memelas, das gorditas e demais delícias da comida mexicana tradicional. O residente de sempre se encontra deslocado frente a esses odores que desconhece, não necessariamente aprecia e que não têm nada a ver com o odor de bebedeira da pulquería [local onde se vende pulque, bebida alcóolica típica mexicana], de óleo requentado dos pontos de tacos ou das velas da loja de artigos religiosos (HIERNAUX-NICOLAS; GONZÁLEZ-GÓMEZ, 2014, p. 11, tradução nossa).

Retomando o conceito de memória, com a "invasão" causada pelo turismo, os lugares de memória (discutidos por Halbwacks, Ricouer, Nora e Pollak), que são os cheiros e sabores da cidade, se perdem - ou mudam para a periferia, pondo em xeque a memória e identidade cultural daquela região.

Outro aspecto a ser destacado da "colonização" turística é o processo de homogeneização dos espaços. Nota-se uma tendência de se padronizarem hospedagem, entretenimento e até mesmo a alimentação, num movimento de internacionalização. Dessa forma, o turista pode "conhecer" um novo local, sem abrir mão dos confortos aos quais está habituado.

Assim, o poder dos novos residentes e visitantes toma posse do bairro. Odores, sons, cores, texturas, tudo forma um conjunto sinestésico que demole progressivamente a paisagem sinestésica do bairro, por pequenas investidas, uma multiplicidade de minúsculas intervenções que pouco a pouco se tornam dominantes e condicionam a aparição de uma nova paisagem sensorial e de novas experiências da vida urbana (HIERNAUX-NICOLAS; GONZÁLEZ-GÓMEZ, 2014, p. 12, tradução nossa).

Contraditoriamente, a valorização turística muitas vezes causou e ainda causa a desvalorização da cultura local. Percebe-se, mais uma vez, que, assim como no pro- 
cesso de formação da gastronomia brasileira, há uma hierarquização de culturas. Uma busca por homogeneização baseada em padrões europeus ou norte-americanos. A cultura popular local é avaliada como menor, como pouco civilizada e, assim, suplantada pelos costumes dos países "desenvolvidos".

Mas o que faz com que o turismo se deturpe dessa forma? Para Krippendorf a explicação é complexa, vai além do simples interesse econômico e inclui uma sociedade voltada para o lazer como forma de escape do cotidiano massacrante.

\begin{abstract}
Nos nossos dias, a necessidade de viajar é sobretudo criada pela sociedade e marcada pelo cotidiano. As pessoas viajam porque não se sentem mais à vontade onde se encontram, seja nos locais de trabaIho, seja onde moram. Sentem necessidade urgente de se desfazer temporariamente da rotina massificante do dia-a-dia do trabalho, da moradia e do lazer, a fim de estar em condições de retomá-la ao regressarem (KRIPPENDORF, 2000, pp. 14-15).
\end{abstract}

A viagem, nessa perspectiva, se tornou uma norma social (KRIPPENDORF, 2000), uma vez que o relaxamento não é mais possível no ambiente doméstico, as férias viram sinônimo de viagem. O modelo de um turismo industrial cria contradições e o sujeito viaja para locais cheios para descansar, em programações com agendas mais cronometradas do que no dia-a-dia, pois as férias têm de ser produtivas. No final das contas, o que o sujeito busca é um descanso do trabalho apenas. $O$ cotidiano se repete nas férias sob formas de outras atividades. "O turismo funciona como terapia da sociedade [...]. Ele exerce um efeito estabilizador não apenas sobre o indivíduo, mas também sobre toda a sociedade e a economia" (KRIPPENDORF, 2000, p. 16).

Nessa linha de análise, o turismo talvez tenha de voltar à sua origem, ser compreendido como um fenômeno de sujeitos que se relacionam, que, na alteridade, se reconhecem no Outro. Atualmente, ressalta Krippendorf, "na maioria dos casos, o encontro segue a lógica de um clichê, é artificial e enganador" (2000, p. 83). Assim, as viagens simplesmente servem para a confirmação de clichês e preconceitos tanto de autóctones para com turistas como o contrário. A viagem como experiência se perde, por que se perde, também, a ideia de autenticidade do local. Num processo semelhante ao que ocorre com a gastronomia local, onde

A relação entre identidade e tipicidade é muito forçada, pois a tipificação não retém a riqueza cultural na qual os pratos, um dia, estiveram imersos. Ao simplificar a relação da comida com a cultura em sentido amplo, dá-se uma caricaturização desta última, fazendo com que os próprios consumidores locais já não mais a reconheçam como autêntica (DÓRIA, 2014, p. 166).

Idealmente, "o turista, percorrendo outras regiões ou países, tem nessa vivência de semelhanças e diferenças uma das razões primeiras das suas práticas" (GASTAL; 
MOESCH, 2007, p. 36). Como então recuperar esse sentido de viagem? O caminho apontado por autores como Krippendorf, Gastal e Moesch está na valorização das comunidades locais e suas diferenças culturais. É nesse ponto que entra a cultura alimentar e a valorização da gastronomia local, com suas especificidades, sua memória e identidade.

Uma política pública de Turismo deve ter como concepção o Turismo como um sistema aberto, orgânico e complexo que se coloque como atividade multissetorial, cuja execução deve, necessariamente, incorporar visões multidisciplinares, multiculturais e multissociais. Assim, se constituirá no trabalho conjunto do setor público com a iniciativa privada e com a sociedade civil, reconstruindo os processos de identidade tão necessários às cidades e às localidades, para que se integrem às redes de globalização de forma independente, em vez de serem homogeneizadas nesse processo." (GASTAL; MOESCH, 2007, p. 45)

Não se trata, portanto, de ignorar os aspectos econômicos do turismo, mas não os colocar como prioridade, acima do bem-estar das populações locais e dos turistas. Nesse sentido, pode-se valorizar a cultura local, ressaltando o que a diferencia de outras, seja na música, na arte, nas tradições ou na gastronomia, tornando-a o grande atrativo turístico da região. No mesmo processo global, abordado anteriormente, que vem ocorrendo com a gastronomia brasileira. Dessa forma, cria-se um produto exclusivo e se valoriza a identidade cultural da população autóctone. "Estudos recentes destacam que, cada vez mais, o que é consumido não são produtos e serviços por si mesmos, mas a aura a eles agregada que se torna significado ou signo emancipado do produto em si" (GASTAL, 2005, p. 56).

\section{APONTAMENTOS FINAIS}

Percebe-se, assim, que os conceitos de cultura, identidade e memória são essenciais para se discutir a importância da gastronomia na vida do sujeito social. $\mathrm{O}$ ato de alimentar-se transcende a necessidade biológica: é, assim como a definição de Geertz para cultura, uma teia de significados.

A gastronomia perpassa as mais diversas esferas da vida do sujeito. Fortemente ligada à memória, a culinária tem papel essencial na formação das identidades coletivas. Afinal, como argumenta Pollak, a memória é um dos elementos constituinte da identidade, tanto individual quanto coletiva, uma vez que ela acentua o sentimento de continuidade e coerência. Seu valor pode ser ainda maior em um tempo que Hall denomina de modernidade tardia, em que o sujeito tem diversas possibilidades de grupos para se identificar. Num cenário em que a fragmentação exacerbada 
da identidade pode gerar ansiedade, a gastronomia surge como uma das formas tradicionais passíveis de serem valorizadas, por trazer o sentido de coerência, num apego à tranquilidade do passado.

No Brasil, a cultura tradicional culinária nesse momento passa por uma redescoberta. Isso porque, no processo de construção da identidade gastronômica nacional, a cultura popular foi frequentemente renegada. No processo de modernização do país, a ideia de progresso e modernidade foi exaltada em detrimento do antigo. Dessa forma, o ideal de civilisation francês teve forte influência na construção da gastronomia brasileira, renegando a culinária tradicional popular, com influências indígenas e africanas, e valorizando a gastronomia de origem europeia.

Pode-se apontar como uma possível consequência desse processo mudanças no senso de identidade culinária nacional. Essa falta de coerência identitária pode ser notada nas classificações da gastronomia brasileira encontradas em guias turísticos: a indicação de pratos típicos regionais é superficial e artificial, uma vez que é baseada na divisão oficial dos estados e não respeita as singularidades locais e o processo histórico de construção dos significados em torno de tais preparos.

Em um contexto de modernidade tardia e de desejo de memória, conceito desenvolvido por Nora, nota-se uma busca pela redescoberta das particularidades locais da gastronomia brasileira, da culinária ligada ao território, da memória gastronômica coletiva singular e não nacional homogeneizada. Parece que esse é o caminho para se desvendar o complexo objeto da Gastronomia Brasileira: entendê-la não de forma generalizada, mas apreendê-la em suas especificidades múltiplas.

Nesse processo, o Turismo, um fenômeno da sociedade moderna que também está em processo de redescoberta, pode ser um grande aliado. Uma vez que o momento é de busca de recuperação do valor do encontro com o Outro na viagem, as especificidades da Gastronomia podem tornar-se um grande atrativo das regiões brasileiras, dando destaque à cultura alimentar local.

Nessa perspectiva é que os diversos aspectos da cultura alimentar brasileira podem ser utilizados em políticas públicas de fomento do turismo gastronômico no país. Não se trata, mais uma vez, de ignorar o turismo como um fenômeno de grande escala, mas valorizar a identidade cultural única de uma população. Ou seja, o turista, ao visitar o Brasil, deve ter contato com a gastronomia brasileira, com suas especificidades locais, com seus saberes-fazer e não apenas ter opções de uma culinária internacionalizada. Essa ele pode encontrar em qualquer lugar do mundo, e justamente por isso não tem relevância na experiência de encontro com a cultural do local visitado. 
Para se alcançar esse objetivo deve-se, no entanto, passar pelo empoderamento da população que ali vive. Isso significa que as políticas públicas não devem ser impostas, mas pensadas, discutidas e construídas com os atores mais interessados, aqueles que construíram e habitam aquela região. E é nesse ponto que entra a gastronomia como um dos fatores a serem trabalhados. Assim, Krippendorf propõe:

As especialidades culinárias e os pratos regionais devem figurar com destaque nos cardápios. E isso não exclui algumas pequenas adaptações (menos tempero, por exemplo) que às vezes são necessárias e podem ser realizadas sem maltratar a cozinha tradicional. É preciso reduzir a oferta da cozinha dita internacional. Também é preciso favorecer as bebidas locais tradicionais (2000, p. 157).

Dessa forma, a valorização da cultura alimentar local - portadora de identidade e memória - surge como um dos caminhos para que o turismo seja o encontro com o Outro, de troca de culturas e experiências, e não apenas um produto mercadológico. De maneira que o reconhecimento de uma cultura alimentar com marcas da cultura brasileira garanta às populações locais a salvaguarda de suas tradições e sua subsistência, em que o turista possa experimentar em sua viagem a singularidade da cultura alimentar de uma localidade.

\section{REFERÊNCIAS BIBLIOGRÁFICAS}

BAUMAN, Zygmunt. Ensaios sobre o conceito de cultura. Rio de Janeiro: Zahar, 2012.

BHABHA, Homi. O Local da cultura. Belo Horizonte: Ed. UFMG, 2003.

BIENASSIS, Loïc. Quelle carte pour quel territoire ? Impossibles et nécessaires : les inventaires du patrimoine alimentaire. Food \& History, v. 9, n. 2, pp. 127-152, 2011.

BRASIL. Ministério Do Turismo. Hábitos de Consumo do Turismo Brasileiro. Disponível em: <http://www.turismo.gov.br/export/sites/default/turismo/noticias/todas_noticias/Noticias_download/13.11.09_Pesquisa_Hxbitos_2009.pdf $>$. Acesso em: 13 abr. 2016.

CASCUDO, Luís da Câmara. História da Alimentação no Brasil. 4. Ed. São Paulo: Global, 2011. COSTA, Everaldo Batista da. Cidades da Patrimonialização Global: simultaneidade totalidade urbana - totalidade mundo. São Paulo: Humanitas, FAPESP, 2015.

DÓRIA, Carlos Alberto. Formação da Culinária Brasileira: Escritos sobre a cozinha inzoneira. São Paulo: Três Estrelas, 2014.

ELIAS, Nobert. O processo civilizador: Uma história dos costumes. Rio de Janeiro: Ed. Jorge Zahar, 1994. 
GASTAL, Susana. Turismo, imagens e imaginários. São Paulo: Aleph, 2005.

GASTAL, Susana; MOESCH, Marutschka. Turismo, políticas públicas e cidadania. São Paulo: Aleph, 2007.

GEERTZ, Clifford. A interpretação das culturas. Rio de Janeiro: Ed. LTC S.A., 1989.

HALBWACHS, Maurice. A memória coletiva. São Paulo: Vértice, Editora dos Tribunais, 1990.

HALL, Stuart. Da diáspora: Identidades e mediações culturais. Belo Horizonte: Editora UFMG, 2003.

. A identidade cultural na pós-modernidade. 11. Ed. Rio de Janeiro: DP\&A, 2006.

HIERNAUX-NICOLAS, Daniel; e GONZÁLEZ-GÓMEZ, Carmen Imelda. Gentrificación, simbólica y poder en los centros históricos: Querétaro, México. In Scripta Nova. Vol. XVIII, n. 493 (12). Espanha: Universidad de Barcelona, 2014.

KRIPPENDORF, Jost. Sociologia do turismo: para uma nova compreensão do lazer e das viagens. São Paulo: Aleph, 2000.

LE GOFF, Jacques. História e Memória. Campinas, SP: Editora da Unicamp, 1990.

MOESCH, Marutschka Martini. A produção do saber turístico. 2 ed. São Paulo, SP: Contexto, 2002.

NORA, Pierre. Revista Projeto História. PUC/SP, no 10, 1993.

POLLAK, Michael. Revista estudos históricos, Rio de Janeiro, vol. 02, no 3, 1989. . Revista estudos históricos, Rio de Janeiro, vol. 05, n 10, 1992.

PROUST, Marcel. Em busca do tempo perdido: no caminho de Swann. vol. 01. 3a ed. São Paulo: Globo, 2006.

RICOEUR, Paul. A memória, a história, o esquecimento. Campinas, SP: Ed. da UNICAMP, 2007.

UNESCO. Declaração Universal Dos Direitos Humanos. Representação da UNESCO no Brasil: Brasília, 1998. 